\title{
Uncanny in the Horror Film: A Reconstructive Study of the Digital Puppet, Ondel Ondel
}

\author{
Ferric Limano* Yasraf Amir Piliang Irma Damajanti Rismiyati E. Koesma \\ Doctoral program in visual Arts and Design, Faculty of Visual Arts and Design \\ Institut Teknologi Bandung, Indonesia \\ E-mail: ferric.limano@gmail.com
}

\begin{abstract}
Uncanny's theory is one of the theories that is often used to produce a sensation of attraction in an individual's emotional state, often used in horror film formulas. The definition of uncanny itself in horror films can be interpreted as supernatural, unreal events, irrational, or something beyond human reason. This will produce feelings of unnatural, terror, even frightening. One of the objects that experience uncanny is puppets, in horror films puppets are often also used as antagonist roles to scare the audience. Ondel-ondel is also a giant puppet made by the Betawi people. This research method is qualitative with learning to uncanny theory through observation of horror films using puppets. The data collected will be used as a reference and reconstructed using digital 3D Ondel-ondel. The purpose of this study is to find out what factors affect the uncanny feeling in horror films, which will produce these factors as a formula that can be recommended to reconstruct horror film scenes.
\end{abstract}

Keywords: Horror, Puppet, Reconstructive, Uncanny

DOI: $10.7176 / \mathrm{ADS} / 99-04$

Publication date: February $28^{\text {th }} 2022$

\section{Introduction}

The ncanny theory is a theory that talks about the emotional reactions of individuals in interacting with objects. In the development of this theory, there are three figures who influence each other in describing this theory. The three figures are Ernest Jentsch, Freud, and Mashahiro Mori. The development and understanding of this theory continue to advance to produce concepts and variables in the theory.

\subsection{Definition Uncanny}

The theory of uncanny starts from viewpoint of Ernst Jentsch in his article entitled "Zur Psychologie des Unheimlichen", translated into English "On the Psychology of the Uncanny" (Jentsch, 1906). Jentsch expressed the meaning of uncanny from German unheimlich, which means someone feels strangeness beyond his perception. This results in feelings of discomfort due to a lack of orientation that forms the basis of thoughts, attention, or tendencies of the general condition of the individual. The uncanny experience of each individual can be different according to the perception and psychological state of each individual.

The uncanny theory was also developed in 1919 by Sigmund Freud. Uncanny theory by Freud focused on the aesthetics produced by the object is not enough, there needs to be an emotional feeling generated after interacting with the object (Freud, 1919). Uncanny feeling according to Freud does not only come from a person's psychological condition but also the condition of the individual's subconscious, which is stored in memory and then becomes perception. Freud also revealed the meaning of uncanny from various vocabularies in Latin (unheimlicher means a different place), Greek (xenos means foreign), English (uncanny means uncomfortable), French (sachs villatte means very bad), Spanish (sospechoso means very bad), Arabic \& Hebrew (khariq liltabiea which means very cruel).

This definition of uncanny developed in Mashahiro Mori's research entitled "Bukimi No Tani", in English Uncanny Valley. This research contains mori experiments in various objects ranging from mechanical robots, robots that resemble human hands (prosthetic hands), puppets, and humans. In these experiments produce different feelings towards individuals in interacting with the object being tested. The experiment concludes is that the more realistic visual objects that resemble humans but have motion simulations that are not the same as humans, will produce an uncanny feeling (terrible, strange, disgusted, scary, and even looks lifeless) (Mori et al., 2012).

\subsection{Concept Uncanny}

The concept is the structure of each individual's consciousness (Solonchak \& Pesina, 2015). The discussion in this point is the concept of uncanny theory that has been expressed by Jentsch, Freud, and Mori to understand the relationship between individual perceptions of objects that produce uncanny.

According to Jentsch the concept of uncanny is related to the word 'new/foreign/hostile' which has the opposite word 'old/known/familiar.' This uncanny feeling arises because there is uncertainty about the object, due to a lack of orientation. Confusion in the individual's perception of everyday life produces this feeling. In 
Jentsch's point of view, uncanny conditions can arise due to the physical atmosphere experienced by individuals through the senses, these external conditions will affect the individual's psyche towards objects with different orientations. According to Harriman the five senses that affect the human soul consist of; sight, hearing, smell, touch, taste (Harriman, 1977).

Furthermore, the concept of uncanny in Freud's view is something that has been recorded in the mind and stored in the subconscious, then when the individual returns to experience this but are different from the stored memory, he will experience an unnatural feeling. Uncanny (the unhomely) is something that is familiar (homely, homey) then reappears in the individual's perception under unnatural conditions (Barnaby, 2015).

In the concept of uncanny theory by Mori in 1940, various experiments were carried out with robot objects. The final conclusion in the experiment mori revealed that a robot that looks like a human but fails to achieve a lifelike appearance will result in horror or a decrease in the individual's empathy for the object. This is expressed in the Uncanny Valley diagram, where there are X and Y axis. The X-axis describes the comparison of the types of sample robots to the experimental object, while the Y-axis displays the results of individual responses to the object. Figure 1 shows the results of Mori's experiment on individual responses called Uncanny Valley.

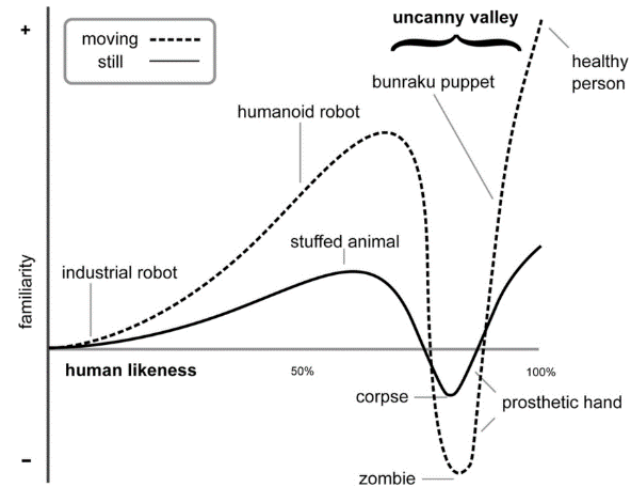

Figure 1. Uncanny Valley (Mori, 1940)

\subsection{Uncanny on Puppet}

In the discussion of uncanny theory by Jentsch and Freud, there are uncanny objects discussed as examples in their case studies. The object of discussion in Jentsch's research is taking samples of marionette puppets / wax statues that are contained in dim light conditions will produce an uncanny feeling.

A case study conducted by Freud discusses phenomena in the opera art of The Sand-Man by Hoffmann. In the story, the figure of the Olympian the puppet is shown, this character is played by humans but is made to move as if it were a mechanic or an automaton. This results in a feeling of uncertainty whether the character is a living being or a mechanical one, the uncertainty displayed gives an uncanny feeling to the witnessing individual. This of course comes from the individual's recording power of humans who have unnatural movements. This condition of ambiguity, or fluctuations in the situation, actually creates an attraction for the audience. The result of this uncanny feeling in opera art results in a mixture of terror and curiosity from the audience (Fuchs, 2019). It is also often used in various industries to create ambiguous conditions in the application of scenes in videos, the phenomenon of feeling for a terrible character produces a horror, terror appeal, which is sought by individuals. how similar human facial expressions and sounds are to lip movements; it is the characters who do not have synchronization that is the most frightening (Tinwell et al., 2010). In digital works of CGI (computer generated imagery) animation with a realistic level displayed to the audience that does not match memory, it will produce the feeling of a dead puppet (Pollick, 2010). This condition arises because there is a blurred distinction between fantasy and reality, which is displayed in an imaginary form (Freud, 2003).

Mori also took the object of Bunraku puppet as an experiment on the uncanny valley diagram, Bunraku puppet is a Japanese puppet show started in the 17th century. Bunraku puppet has visuals that resemble humans, within a certain distance the audience can ignore the resemblance to humans. However, if you pay close attention, there are irregularities in this bunraku puppet object, especially in its movements.

Ondel-ondel is a performing art featuring giant puppets from the Indonesian Betawi society, this Ondelondel performing art is performed using typical Betawi music accompaniment by walking and dancing (Dewanti, 2014). In this study, Ondel-ondel was used as the object of the case study because here are some reasons for using Ondel-ondel as the object of research; Ondel-ondel was chosen because it has a complete variable of visual and motion. In visual variables, Ondel-ondel has experienced a history of change that has human personification, ranging from barongan to modern Ondel-ondel today (Purbasari et al., 2019). This has a condition between the boundary and reality that is intended in the uncanny concept.

The purpose of the study is to understand the uncanny feelings shown in the horror movie scenes using 
puppets, so that a descriptive explanation is produced about the factors that influence individual feelings towards the uncanny object. The object limitation used for visual and motion reconstruction is digital Betawi Ondelondel in $3 \mathrm{D}$.

\section{Method}

This study uses a qualitative method through collecting video data from horror movie scenes using puppets as characters who experience uncanny. Then selected scenes that can be applied in the process of visual and motion reconstruction on digital Ondel-ondel. The results of the reconstruction will be explained through literature study, until finally producing a descriptive explanation of the factors that influence the uncanny feeling in the puppet horror movie scene.

\section{Result and Discussions}

The experiment on Ondel-ondel 3D is divided into two main components, namely visual and motion, the initial visual of Ondel-ondel 3D is taken from the internet website at 3dwarehouse.sketchup (Ajitec, 2018). This initial data will be used for the reconstruction process in horror movie scenes. The initial data is carried out by the efficiency process for the number of polygons.

\subsection{Puppet Horror Film}

As seen in the background, conditions of high ambiguity, uncertainty, and unnaturalness are used to generate attraction and individual curiosity towards objects. This is a philosophical concept in postmodernism design where the language of "schizophrenic", the language of confusion, uncertainty. Confusion becomes interesting, because the signifier (word/language) and signified (concept/thing) cannot be interpreted directly (Amir et al., 2001).

In horror films, individuals are not looking for feelings of pleasure, but individuals are looking for feelings of fear, terror, or something unnatural in every scene of the film. The following is a collection of 20 scary horror movie scenes using puppet objects (Watchmojo, 2020). The author takes the top three samples from this sequence, namely; first Chuckie the puppet, Anabelle, and Billy the saw.

Table 1. Horror Movie Scenes Using Puppets

\begin{tabular}{|l|l|l|}
\hline Movie title & Scene Pictures & Scene Explanation \\
\hline Chucky & $\begin{array}{l}\text { Chucky's scene changes positions, then the human } \\
\text { character opens the back of the puppet to make sure the } \\
\text { battery is installed. But the is no battery and the head } \\
\text { rotates } 180^{\circ}, \text { issuing the dialogue "hi I'm Chucky wanna } \\
\text { play". }\end{array}$ \\
\hline Annabelle & & $\begin{array}{l}\text { The Annabelle puppet moves from room to room giving } \\
\text { an unnatural feeling to the human character, screaming in } \\
\text { terror at the sight of this puppet. }\end{array}$ \\
\hline Billy The Saw & & $\begin{array}{l}\text { Billy's character comes out of a dark area on a small } \\
\text { bicycle, inviting him to play a game. Then he issued a } \\
\text { dialogue "most people are so ungrateful to be alive". }\end{array}$ \\
\hline
\end{tabular}

Technically, the shooting of this film scene has similarities, where video shooting is done with a medium shot. Medium shot itself is a wide shot on the head, chest or even up to the character's waist (Brown, 2016). Medium shot aims to convey the emotions of the characters to the audience or between characters who are doing dialogue in the film (Canini et al., 2013). Because it is seen in scenes that want to convey emotional feelings to the audience using medium shot images.

Then in the lighting in the film Anabelle and Billy the Saw have in common, namely lowkey, lowkey itself 
aims to give a dramatic impression in the condition of the individual's soul. The use of light is done by providing a contrast between each part of the character and the background. Gives a mysterious, spooky and gloomy feeling (Nurcahyo, 2019).

For the Chukkie film, this lighting does not use only normal or ordinary light, but the narrative that is built up to the scene is very good. Where the human character sees the puppet has no battery but can move suddenly, this will give a strange feeling when the story is conveyed to the audience. The storytelling process in a strong script will give indirect meaning, but in the subconscious, the individual experiences an unnatural feeling towards the scene, resulting in feelings of fear and terror. Stories have supernatural elements, events that seem unreal, irrational, or something rational but beyond human reason, disturbing, unnatural, surprising, unexpected (Prohászková, 2012). Not only that in the chuckie film there is also a very strange movement where the head rotates $180 \mathrm{o}$, this unnatural movement in the uncanny concept will produce a feeling of fear in the individual. Some things on the character that affect the emotional feelings of individuals include; facial expressions, vocal expressions (character's mouth), posture or body movements, and movements (Hanich, 2019).

\subsection{Reconstructive Process}

From the above learning, it can be understood that several factors that influence uncanny feelings towards individuals consist of Film shooting (medium shot), lighting (low key), irrational stories, poses, expressions, and character movements. Through these factors, visual and motion elements will be reconstructed, through the application of digital Betawi Ondels. The following is the process of reconstructing a horror movie scene using 3D Betawi Ondel-ondel:

Table 2. Reconstructive Process Horror Movie Scenes using 3D Ondel-ondel

\begin{tabular}{|c|c|c|}
\hline Process Description & Figure & \\
\hline $\begin{array}{l}\text { Ondel-ondel } 3 \mathrm{D} \text { are neatly made in terms of the } \\
\text { number of polygonals, then the layout is set with a } \\
\text { camera and lights in the } 3 \mathrm{D} \text { editor. The camera is } \\
\text { placed behind the } 3 \mathrm{D} \text { Ondel-ondel object, then the } \\
\text { light is placed at } 3 / 4 \text { angle of the object. }\end{array}$ & & $\underline{a}$ \\
\hline $\begin{array}{l}\text { The lamp used is only one, namely spotlight, in order } \\
\text { to provide contrast between light and shadow. With the } \\
\text { aim of giving the same appearance as the scene in the } \\
\text { sample horror movie scene. }\end{array}$ & & 3 \\
\hline $\begin{array}{l}\text { The camera uses a rule of third composition and a } \\
\text { medium shot to convey a clear look on Ondel-ondel's } \\
\text { face. The target is to convey Ondel-ondel's emotions to } \\
\text { the audience, then an animation of the head rotates } \\
180^{\circ} \text {. Thus, ondel-ondel visually and in motion has } \\
\text { produced an uncanny feeling to the individual. }\end{array}$ & & \\
\hline $\begin{array}{l}\text { The next process is rendering, converting the } 3 \mathrm{D} \text { file } \\
\text { into a collection of images to be made into a movie. } \\
\text { After the rendering is complete, the compositing } \\
\text { process is carried out, by changing the color to } \\
\text { contrast, adding a cool filter (blue color) which is } \\
\text { commonly used in horror films. }\end{array}$ & $\frac{16}{5}$ & 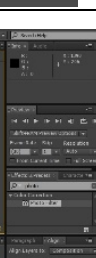 \\
\hline
\end{tabular}


In Figure 2, the final result of the reconstruction of the horror film scene using Ondel-Ondel 3D is shown.

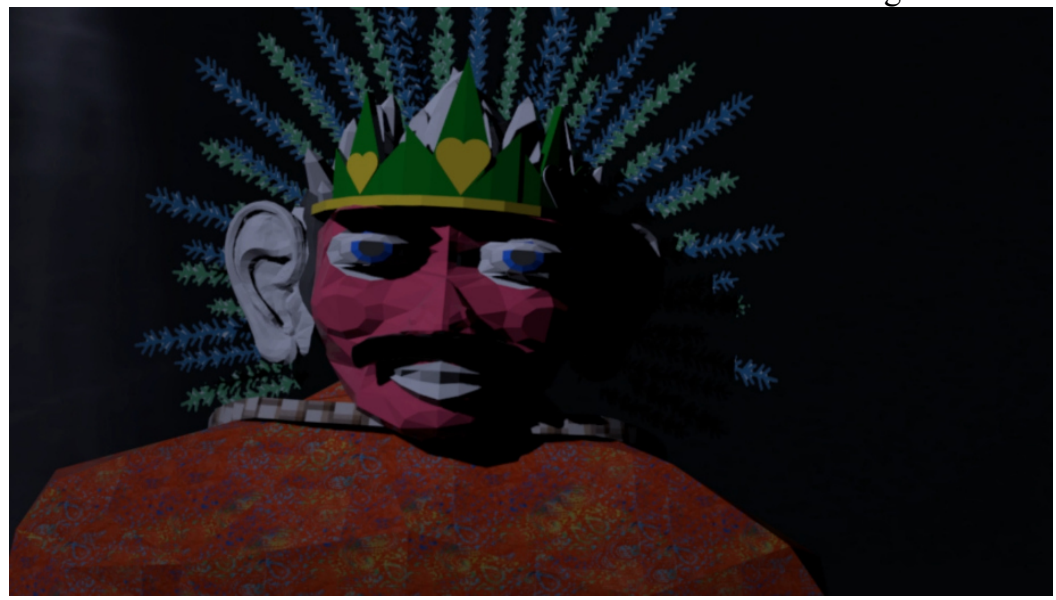

Figure 2. Horror Movie Scene Reconstruction Using 3D Ondel-ondel

\section{Conclusion}

Uncanny is a natural phenomenon in individuals' feelings towards objects that are not natural in orientation, but this is a new way to generate attraction to individuals in the case of horror films that use puppet objects. Film images (medium shot), lighting (low key), irrational stories, poses, expressions, and character movements. These factors can be a formula for how to produce scenes that can cause feelings of uncanny to individuals. In further research, it may be possible to use quantitative methods to direct individual responses, in order to produce stronger validity for the factors that have been found in this study.

\section{References}

Ajitec. (2018). Ondel-ondel. https://3dwarehouse.sketchup.com/model/7c94ec0d-03e7-4ce9-a1414ad97cc4flf0/Ondel-Ondel?hl=en\&login=true\#.

Amir, Y., Posmodernisme, P., Komunikasi, E., \& Piliang, Y. A. (2001). Posmodernisme dan Ekstasi Komunikasi. Mediator: Jurnal Komunikasi, 2(2).

Barnaby, A. (2015). "After the event": Freud's uncanny and the anxiety of origins. In Psychoanalytic Quarterly. https://doi.org/10.1002/psaq.12045

Brown, B. (2016). Cinematography: Theory and practice: Image making for cinematographers and directors: Third edition. In Cinematography: Theory and Practice: Image Making for Cinematographers and Directors: Third Edition. https://doi.org/10.4324/9781315667829

Canini, L., Benini, S., \& Leonardi, R. (2013). Affective recommendation of movies based on selected connotative features. IEEE Transactions on Circuits and Systems for Video Technology, 23(4). https://doi.org/10.1109/TCSVT.2012.2211935

Dewanti, A. R. (2014). Ondel-ondel sebagai ikon seni tradisi Betawi. Prosiding Seminar Nasional Seni Tradisi Keragaman Tradisi Sebagai Warisan Budaya .

Freud, S. (2003). The Uncanny. Penguin Classics.

Freud, S. (1919). The 'Uncanny.' An Infantile Neurosis and Other Works, XVII(The Standard Edition of the Complete Psychological Works of Sigmund Freud), 217-256.

Harriman, P. L. (1977). Handbook of psychological terms. Litlefield: Adams \& Company.

Hanich, J. (2019). Cinematic Emotion in Horror Films and Thrillers. Journal Für Kunstgeschichte, 19(1). https://doi.org/10.11588/jfk.2015.1.57952

Jentsch, E. (1906). On the Psychology of the Uncanny ("Zur Psychologie des Unheimlichen”, Translated by Roy Sellars, online at: http://www.cpmg.org.br/artigos/on_the_psychology_of_the_uncanny.pdf). PsychiatrischNeurologische Wochenschrift.

Mori, M., MacDorman, K. F., \& Kageki, N. (2012). The uncanny valley. IEEE Robotics and Automation Magazine. https://doi.org/10.1109/MRA.2012.2192811

Nurcahyo, D. E. (2019). TATA CAHAYA LOW KEY DALAM FILM ANIMASI STOP-MOTION CORPSE BRIDE KARYA TIM BURTON. Texture, 2(1).

Pollick, F. E. (2010). In search of the uncanny valley. Lecture Notes of the Institute for Computer Sciences, Social-Informatics and Telecommunications Engineering. https://doi.org/10.1007/978-3-642-12630-7_8

Purbasari, M., Marianto, M. D., \& Burhan, M. A. (2019). Ondel-ondel kekinian: boneka besar Betawi di zaman modern. Productum: Jurnal Desain Produk (Pengetahuan Dan Perancangan Produk). https://doi.org/10.24821/productum.v3i6.2429 
Prohászková, M. V. (2012). The Genre of Horror. American International Journal of Contemporary Research, 2(4).

Solonchak, T., \& Pesina, S. (2015). Concept and its Structure. Procedia - Social and Behavioral Sciences. https://doi.org/10.1016/j.sbspro.2015.06.050

Tinwell, A., Grimshaw, M., \& Williams, A. (2010). Uncanny behaviour in survival horror games. Journal of Gaming and Virtual Worlds. https://doi.org/10.1386/jgvw.2.1.3_1

Watchmojo. (2020). Top 20 Scariest Puppets in Horror Movies. https://www.youtube.com/watch?v=DTbpzQVwCm8 